\title{
Comparison of Anthropometric Indices in Predicting the Risk of Hypertension, Iran - 2014
}

\author{
Hossein Lashkardoost, Fateme Hoseyni' ${ }^{1}$ Elham Rabbani', Farzane Qorbani Moqadam¹, Leila Hosseini², Salimeh Azizi ${ }^{3}$, Andishe Hamedi \\ Departments of Epidemiology and Biostatistics, ${ }^{1}$ Public Health, ${ }^{2}$ Cardiology and ${ }^{3}$ Faculty of Nursing, North Khorasan University of Medical Sciences, Bojnurd, Iran
}

\section{Abstract}

Purpose: The best anthropometric index has not been established to investigate the relationship between hypertension and obesity. Since a similar study was not conducted in Bojnurd, we began to investigate the comparison of anthropometric indices (body mass index, waist circumference, and waist-to-hip and waist-to-height ratios) in predicting the risk of hypertension. Materials and Methods: The present cross-sectional study was conducted on women referring to Bojnurd health centers. For analyzing the data, we used $t$-test, Chi-square, logistic regression, and the receiver operating characteristic curve in SPSS 19 software. Results: The prevalence of blood pressure was $53.4 \%$ (confidence interval $=46.8-60$ ). All four anthropometric indicators were used as a screening tool for hypertension diagnosis; however, body mass index (BMI) had a higher sub-curved surface than other anthropometric indices (area under curve $=0.717$ ). The cutoff point of BMI for predicting the risk of hypertension was 25.6. Conclusions: This study suggested that BMI as an anthropometric indicator to evaluate the risk of hypertension. Since a significant percentage of people are unaware of the existence of hypertension, continuing education is needed to encourage people to pay more attention to this problem.

Keywords: Body mass index, hypertension, waist circumference, waist-to-height ratio, waist-to-hip ratio

\section{INTRODUCTION}

Urbanization, industrialization, and population growth have led to an increase in the prevalence of chronic diseases worldwide. Obesity as a risk factor for noncommunicable diseases is one of the most important public health problems worldwide. ${ }^{[1]}$ Obesity refers to the abnormal accumulation of fat in the body tissue. ${ }^{[2]}$ The prevalence of obesity is increasing, and obese people are prone to chronic diseases such as Type 2 diabetes, hypertension, cardiovascular disease, and some cancers. ${ }^{[3]}$ Due to its economic burden, choosing the best measure to monitor the complications of obesity in the population is very important. Body mass index (BMI) is the most commonly used index for assessing obesity. Other anthropometric indices, such as waist circumference (WC), waist-to-hip ratio (WHR), and waist-to-height ratios (WHtR), have recently been suggested and are considered for the distribution of fat in the body. ${ }^{[4,5]}$ The WC gives us information on how the body's fat is distributed, indicating abdominal obesity. ${ }^{[6]}$ Some environmental factors, including obesity, are effective in high blood pressure. The prevalence of hypertension in obese people is higher than in normal people, ${ }^{[5]}$ and it varies from one country to another,

\begin{tabular}{|l|l|}
\hline \multicolumn{3}{c|}{ Access this article online } \\
\hline Quick Response Code: & Website: \\
& \\
http://www.ijcva.com
\end{tabular}

from $10 \%$ to over $60 \%$ in different countries. ${ }^{[7]}$ About $18 \%$ of global deaths have been attributed to hypertension. It causes one of the eight deaths in the world. ${ }^{[8]}$ It is the most important health issue in developed and developing countries. ${ }^{[9]}$ The prevalence of hypertension in the 25-64 years' Iranian population was $22.1 \%$ in $2015 .{ }^{[10]}$ The risk of developing hypertension in individuals with abnormal BMI is proportional to the increase in WC. ${ }^{[5]}$ North Khorasan Province has been ranked first regarding age-related blood pressure in women. The prevalence of hypertension in women of North Khorasan province is $42.7 \% .{ }^{[11,12]}$ Hence, using simple and inexpensive methods to diagnose, especially the distribution of obesity in the body, help us to identify people at high risk for chronic diseases such as blood pressure. By decreasing the prevalence of obesity, through prevention and education, we will see a

Address for correspondence: Mrs. Andishe Hamedi, Shirvan Center of Higher Health Education, North Khorasan University of Medical Sciences, Shirvan, Iran. E-mail: ahamedi1364@gmail.com

This is an open access journal, and articles are distributed under the terms of the Creative Commons Attribution-NonCommercial-ShareAlike 4.0 License, which allows others to remix, tweak, and build upon the work non-commercially, as long as appropriate credit is given and the new creations are licensed under the identical terms.

For reprints contact: reprints@medknow.com

How to cite this article: Lashkardoost H, Hoseyni F, Rabbani E, Moqadam FQ, Hosseini L, Azizi S, et al. Comparison of anthropometric indices in predicting the risk of hypertension, Iran - 2014. Int J Cardiovasc Acad 2018;4:77-81. 
significant reduction in the prevalence of hypertension. Since a similar study has not been conducted in Bojnurd, this study was done to determine the best anthropometric index and determine the optimal cutoff point for each of these indicators to predict the risk of hypertension.

\section{Materials and Methods \\ Ethics}

This article was approved by the code "93P767" in North Khorasan University of Medical Sciences, Iran. We get consent from each participant.

\section{Study design}

The present study was a cross-sectional study, and the statistical population was women referring to health centers in Bojnurd. We used cross-sectional sample size formula, based on the prevalence of hypertension 30\%, accuracy of $0.06 \%$, and confidence level of $95 \%$ to estimate the sample size. Finally, we examined 230 people. We used multistage sampling methods from health centers of Bojnurd in five geographic regions of North, South, East, West, and Center. Then, we chose one center randomly from each region. We randomly selected the participants from the centers. Then, we conducted the coordination (on a telephone) for them who were willing to participate in the study after explaining the purpose of the study for them and getting consent; then, we measured anthropometric indices of each one in the health center. The criteria for entry were all women (married) referred to health centers, in which, they were willing to participate in the study. Excluded criteria were as follows: not having a history of exercise and exercise therapy to control or reduce weight gain. After obtaining satisfaction, the questions were asked by the trained person using a questionnaire and an interview. We measured hypertension, with pressure gauge. People, with systolic blood pressure $\geq 140 \mathrm{mmHg}$ or diastolic pressure $\geq 90 \mathrm{mmHg}$, were considered as people with hypertension based on the definition of hypertension published by the Seventh Joint National Committee on Prevention. The weight of the participants was measured using an Omron digital scale manufactured in Japan. Furthermore, a meter was used to measure the height of the people in $\mathrm{cm}$. The BMI was obtained as weight (in $\mathrm{kg}$ ) divided by the square of the height $\left(\right.$ in $\mathrm{m}^{2}$ ). The hip circumference was also measured similar to the WC at the widest part of the buttocks, and then WHR calculated by dividing the $\mathrm{WC}$ to the hip circumference in $\mathrm{cm}$. The WC was also divided by the height to obtain WHtR.

\section{Statistics}

To analyze the data, we used $t$-test, logistic regression model, the receiver operating characteristic (ROC) curve and area under curve (AUC), Youden's Index (J), and the maximum potential effectiveness of a biomarker to measure the power of each anthropometric index in predicting the risk of hypertension in SPSS 19 software, version 19.0 (IBM Corp., Armonk, NY) by using 95\% of confidence interval level.

\section{RESULTS}

In this cross-sectional study, 230 women were enrolled in the study. The mean age of the women, who participate in the study, was $41.1 \pm 15.2$ years, with an average pregnancy rate of $3 \pm 0.14$. The prevalence of blood pressure was $53.4 \%$ (confidence interval $=46.8-60$ ). Demographic characteristics of the study are shown in Table 1.

The mean anthropometric indices of BMI, WC, WHR, and WHtR were higher in participants with hypertension than those without hypertension $(P<0.001)$. There was a statistically significant difference in physical activity between the two groups $(P=0.02)$. The odds ratio of hypertension obtained from anthropometric indices before and after adaptation for age variables, occupation, level of education, number of pregnancies, and physical activity is shown in Table 2 .

In the first model, from four anthropometric indices, BMI, and WHR had a significant relationship with the risk of hypertension. After entering the confounding variables, BMI, WC, and WHtR showed a significant relationship, so that the risk of hypertension in people with $\mathrm{BMI} \geq 27$ greater than $<27$. To compare the predictive power of anthropometric indices, for the risk of hypertension, we used the ROC curve and the sub-curved surface (AUC) [Figure 1].

To determine the risk of hypertension, the best cutoff point for anthropometric indices is shown in Table 3 . The best cutoff point for BMI was $25.65 \mathrm{~kg} / \mathrm{m}^{2}$. Furthermore, the cutoff point of WHtR was 0.52 , and the cut-off point of WHR was 0.94 .

\begin{tabular}{|c|c|c|c|}
\hline Variables & $\begin{array}{c}\text { With } \\
\text { hypertension }\end{array}$ & $\begin{array}{c}\text { Without } \\
\text { hypertension }\end{array}$ & $P$ \\
\hline $\mathrm{n}$ & 123 & 107 & \\
\hline Age & $44.1 \pm 16.5$ & $37.4 \pm 12.9$ & 0.001 \\
\hline BMI & $21.4 \pm 2.5$ & $24.3 \pm 3.3$ & $<0.001$ \\
\hline WC & $101.6 \pm 9.7$ & $92.06 \pm 13.1$ & $<0.001$ \\
\hline WHtR & $0.6 \pm 0.07$ & $0.57 \pm 0.08$ & 0.02 \\
\hline WHR & $0.93 \pm 0.06$ & $0.87 \pm 0.07$ & $<0.001$ \\
\hline \multicolumn{4}{|c|}{ Number of pregnancy } \\
\hline$\leq 2$ & $46(37.4)$ & $59(55.2)$ & 0.018 \\
\hline $2-5$ & $57(46.3)$ & $39(36.4)$ & \\
\hline$>5$ & $20(16.3)$ & $9(8.4)$ & \\
\hline \multicolumn{4}{|l|}{ Occupation } \\
\hline Housewife & $108(87.8)$ & $88(82.2)$ & 0.23 \\
\hline Employee & $15(12.2)$ & $19(17.8)$ & \\
\hline \multicolumn{4}{|l|}{ Level of education } \\
\hline Under diploma & $90(73.2)$ & $55(51.4)$ & 0.003 \\
\hline Diploma & $19(15.4)$ & $30(28)$ & \\
\hline Academic & $14(11.4)$ & $22(20.6)$ & \\
\hline \multicolumn{4}{|l|}{ Regular exercise } \\
\hline No & $116(94.3)$ & $91(85)$ & 0.02 \\
\hline Yes & $7(5.7)$ & $16(15)$ & \\
\hline
\end{tabular}

*Significant at $95 \%$ confidence level. BMI: Body mass index, WC: Waist circumference, WHtR: Waist-to-height ratio, WHR: Waist-to-hip ratio 
The cut-off point of WC was 101, although WC had a lower surface area under the ROC curve than other anthropometric indices.

For comparison in pairs between $\mathrm{BMI}$ and $\mathrm{WC}, P=0.0012$; however, the surface area under the ROC curve was higher in BMI. Similar to BMI versus WHR: 0.015 and BMI versus WHtR: 0.0057. For comparison in pairs between WC versus WHR, $P=0.12$, WC versus WHtR: 0.2 and WHR versus WHtR: 0.38, which means WC, WHR, and WHtR had similar predictive power in the risk of hypertension.

\section{Discussion}

In this study, all four anthropometric indicators were significantly different between the two groups with and without hypertension; ${ }^{[13]}$ however, BMI had a higher AUC than other anthropometric indices like study conducted by Fuchs. ${ }^{[14]}$ However, in a study that conducted in Spanish, the AUC for BMI was significantly higher than the AUCs for WC and WHtR like this study $(\mathrm{AUC}=0.717) .{ }^{[15]}$ Some study shows WHtR is a better predictor for hypertension, which is contradicted with this study. ${ }^{[16]}$

\begin{tabular}{|c|c|c|c|c|}
\hline Variables & OR (95\%Cl) & $P$ & OR (95\%Cl)** & $P$ \\
\hline \multicolumn{5}{|l|}{ BMI } \\
\hline$<22$ & 1 & & 1 & \\
\hline $23.5-25.6$ & $1.5(0.7-3.2)$ & 0.23 & $1.2(0.4-3.1)$ & 0.67 \\
\hline$\geq 25.6$ & $7.6(3.1-18.2)$ & $<0.001$ & $13.9(4.5-43.1)$ & $<0.001$ \\
\hline \multicolumn{5}{|l|}{ WC } \\
\hline$<93$ & 1 & & 1 & \\
\hline 93-97.9 & $1.06(0.4-2.6)$ & 0.88 & $0.2(0.04-1.3)$ & 0.11 \\
\hline$\geq 98$ & $1.2(0.7-2.1)$ & 0.41 & $0.07(0.01-0.4)$ & 0.005 \\
\hline \multicolumn{5}{|l|}{ WHR } \\
\hline$<0.86$ & 1 & & 1 & \\
\hline $0.86-0.89$ & $1.4(0.5-3.4)$ & 0.43 & $1.06(0.3-3.5)$ & 0.92 \\
\hline$\geq 0.9$ & $1.9(1.1-3.6)$ & 0.02 & $0.7(0.2-2.2)$ & 0.6 \\
\hline \multicolumn{5}{|l|}{ WHtR } \\
\hline$<0.50$ & 1 & & 1 & \\
\hline $0.50-0.52$ & $1.2(0.5-2.6)$ & 0.58 & $3.01(0.7-12.7)$ & 0.13 \\
\hline$\geq 0.52$ & $1.6(0.8-2.9)$ & 0.11 & $9.2(1.3-62.6)$ & 0.02 \\
\hline
\end{tabular}

*Significant at $P<0.05, * *$ After adjusting for confounders. BMI: Body mass index, WC: Waist circumference, WHtR: Waist-to-height ratio, WHR: Waist-to-hip ratio, OR: Odds ratio, CI: Confidence interval
Waist-to-hip indices were a good predictor for the risk of hypertension in some studies, which was contradicted with this study. ${ }^{[17]}$ However, such studies have shown that WC is most closely correlated with changes in blood pressure. ${ }^{[18,19]}$ In this study, results showed that BMI, WC, and WHtR had a significant relationship with the risk of hypertension after controlling for confounders such as age, occupation, level of education, number of pregnancies, and physical activity. Furthermore, by analyzing ROC curves, it showed that BMI is the best prediction for the risk of hypertension compared to other anthropometric indicators. WHR, WC, and WHtR are also showed similar predictive power. In a cross-sectional study conducted by Liu, the AUC values did not differ between BMI, WC, and WHtR for prediction of hypertension, which was different with this study. ${ }^{[20]}$

In a meta-analysis study, in the world that compared $\mathrm{WC}$, WHtR, and BMI indices, WHtR was the best indicator for measuring obesity. ${ }^{[21]}$ In the study conducted by Zabetian in Tehran, ${ }^{[22]}$ the cutoff point for WC was 94.5 as a predictor for the risk of cardiovascular disease. Furthermore, according to the National Committee of Obstetrics, WC $\geq 90$ had been suggested for obesity, which was different with this study. This committee recommends a $\mathrm{WC} \geq 95 \mathrm{~cm}$ for appropriate medical interventions. Our estimate is also up to 101. The cutoff points for BMI, WHR, and WHtR were 25.6, 0.52, and 0.94 in this study, respectively. Each population, depending on the race and ethnicity, has a different cutoff point for anthropometric indices related to the risk of developing diseases such as

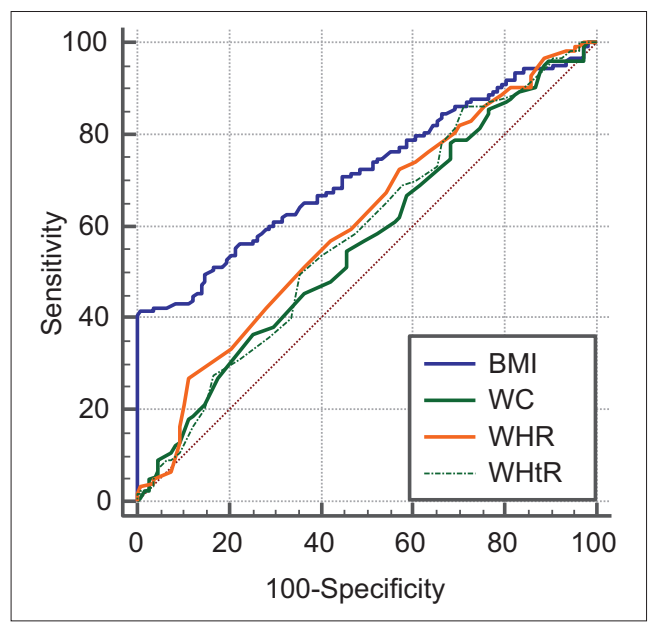

Figure 1: Comparison of receiver operating characteristic curves

Table 3: Areas under the receiver operating characteristic curve, cutoff points, sensitivity, and specificity of anthropometric measurements to predict hypertension

\begin{tabular}{lccccc}
\hline Variables & AUC (95\% CI) & $\boldsymbol{P}$ & Cut-off points & Sensitivity & Specificity \\
\hline BMI & $0.71(0.65-0.77)$ & $<0.001$ & 25.65 & 40.65 & 36.5 \\
WC & $0.56(0.49-0.62)$ & 0.09 & 101 & 26.8 & 0.4 \\
WHR & $0.6(0.53-0.66)$ & 0.004 & 0.94 & 84.7 \\
WHtR & $0.58(0.51-0.64)$ & 0.03 & 0.52 & 86.1 & 0.15 \\
\hline
\end{tabular}

AUC: Area under curve, BMI: Body mass index, WC: Waist circumference, WHtR: Waist-to-height ratio, WHR: Waist-to-hip ratio, OR: Odds ratio, CI: Confidence interval 
blood pressure. Different cutoff points are estimated for anthropometric indices. These differences may be due to the differences in lifestyle because of the dietary habits and physical activity of the population under the study as well as the differences in the study outcomes found in the prediction models. Cutting points that show the highest probability of predicting the risk of hypertension based on sensitivity and specificity were similar to recommended values ${ }^{[13,23]} \mathrm{WC}$ does not consider the person's height in the risk assessment, it was not significantly a good predictor for hypertension; therefore, it can be said that because the WHtR index considers the height of people in measuring body mass, in contrast to $\mathrm{WC}$, is more sensitive than other anthropometric indices in identifying patients with hypertension. In this study, the prevalence of hypertension was $53.4 \%$. In comparison with other parts of the country, the prevalence rate of hypertension was $23.7 \%$ in Tehran, ${ }^{[24]}$ and $27.3 \%$ in Isfahan. ${ }^{[25]}$ There is a significant difference in the prevalence of hypertension in different parts of the world. In the United States, it was $30.1 \% ;^{[26]}$ and in Canada, it was $21.6 \% .^{[27]}$ The prevalence of hypertension in the study conducted by Ana was $44 \% .{ }^{[13]}$ Several studies have reported the increasing incidence of hypertension, especially in women in developing countries, including Iran. In this study, the abdominal obesity was one of the factors that influenced women's hypertension. Such studies confirm our results. ${ }^{[28,22]}$ In this study, age had a major risk of hypertension. Such studies have reported similar results. ${ }^{[24,30]}$ However, Anane's study did not report a significant relationship between the age and hypertension which may be due to differences in the age group of the study. ${ }^{[31]}$ In the present study, there was a significant relationship between regular exercise and hypertension. Some studies reported inconsistent results with our study. ${ }^{[32,33]}$ Maybe few people in the two study groups had reported doing exercise in their leisure time. However, such studies have shown that by reducing physical activity, the risk of hypertension would increase.$^{[31,34]}$ Hence, people, who do not have physical activity in the day, are twice more susceptible to having higher blood pressure. The present study shows that the number of pregnancies is one of the factors that increase the blood pressure in women. Such studies have reported similar results. ${ }^{[35]}$ In this study, there was no significant relationship between female occupation and their education level with hypertension. The results of such studies contradicted our study. ${ }^{[31,33]}$

\section{Conclusion}

Overall, this study indicated that BMI, WC, WHR, and WHtR had affected on blood pressure in women since BMI had better surface area under the ROC curve. Since a significant percentage of people are unaware of the existence of hypertension, and controls of this disorder are not appropriate in many people, continuing education is needed to encourage people to pay more attention to this problem. Since obesity and hypertension are important risk factors for cardiovascular disease, the need for nutritional education with a change in attitude is necessary as a result of weight control and fitness. There were some limitations in this study. The main limitation of our study was its cross-sectional design, and it was impossible to show the cause-effect relationship. We propose a prospective study on a large population of men and women because this study has been done only on women.

\section{Acknowledgment}

This article was approved by the code "93P767" in North Khorasan University of Medical Sciences, Iran. The authors would like to thank all participants who participate in the present study.

\section{Financial support and sponsorship}

Nil.

\section{Conflicts of interest}

There are no conflicts of interest.

\section{RefERENCES}

1. Poirier P, Lemieux I, Mauriège P, Dewailly E, Blanchet C, Bergeron J, et al. Impact of waist circumference on the relationship between blood pressure and insulin: The quebec health survey. Hypertension 2005;45:363-7.

2. Pi-Sunyer X. The medical risks of obesity. Postgrad Med 2009;121:21-33.

3. Huxley R, Mendis S, Zheleznyakov E, Reddy S, Chan J. Body mass index, waist circumference and waist: hip ratio as predictors of cardiovascular risk - A review of the literature. Eur J Clin Nutr 2010;64:16-22.

4. Janssen I, Katzmarzyk PT, Ross R. Waist circumference and not body mass index explains obesity-related health risk. Am J Clin Nutr 2004;79:379-84.

5. Kabalin M, Kolarić B, Marchesi VV, Pereza N, Ostojić S, Rukavina T, et al. Body mass index, waist circumference and waist-to-hip ratio: Which anthropometric indicator is better predictor for the hypertension development in women population of the Island Cres. Coll Antropol 2012;36:363-8.

6. Siani A, Cappuccio FP, Barba G, Trevisan M, Farinaro E, Lacone R, et al. The relationship of waist circumference to blood pressure: The olivetti heart study. Am J Hypertens 2002;15:780-6.

7. Lawes CM, Vander Hoorn S, Rodgers A, International Society of Hypertension. Global burden of blood-pressure-related disease, 2001. Lancet 2008;371:1513-8.

8. World Health Organization. The World Health Report 2002: Reducing Risks, Promoting Healthy Life. Geneva, Switzerland: World Health Organization; 2002.

9. Demisse AG, Greffie ES, Abebe SM, Bulti AB, Alemu S, Abebe B, et al. High burden of hypertension across the age groups among residents of Gondar city in Ethiopia: A population based cross sectional study. BMC Public Health 2017;17:647.

10. Malekzadeh MM, Etemadi A, Kamangar F, Khademi H, Golozar A, Islami F, et al. Prevalence, awareness and risk factors of hypertension in a large cohort of Iranian adult population. J Hypertens 2013;31:1364-71.

11. Mohammadi M, Mirzaei M. Population attributable fraction of hypertension associated with obesity in Iran. J Community Health Res 2016;5:249-59.

12. Mohammadi M, Mirzaei M. Population-attributable fraction of hypertension associated with obesity, abdominal obesity, and the joint effect of both in the central provinces of Iran. J Epidemiol Glob Health 2017;7:71-9.

13. Rezende AC, Souza LG, Jardim TV, Perillo NB, Araújo YCL, de Souza SG, et al. Is waist-to-height ratio the best predictive indicator of hypertension incidence? A cohort study. BMC Public Health 2018;18:281.

14. Fuchs FD, Gus M, Moreira LB, Moraes RS, Wiehe M, Pereira GM, et al. Anthropometric indices and the incidence of hypertension: 
A comparative analysis. Obes Res 2005;13:1515-7.

15. Guasch-Ferré M, Bulló M, Martínez-González MÁ, Corella D, Estruch R, Covas MI, et al. Waist-to-height ratio and cardiovascular risk factors in elderly individuals at high cardiovascular risk. PLoS One 2012; 7:e43275.

16. Li WC, Chen IC, Chang YC, Loke SS, Wang SH, Hsiao KY, et al. Waist-to-height ratio, waist circumference, and body mass index as indices of cardiometabolic risk among 36,642 Taiwanese adults. Eur J Nutr 2013;52:57-65.

17. Dobbelsteyn CJ, Joffres MR, MacLean DR, Flowerdew G. A comparative evaluation of waist circumference, waist-to-hip ratio and body mass index as indicators of cardiovascular risk factors. The canadian heart health surveys. Int J Obes Relat Metab Disord 2001;25:652-61.

18. Gustat J, Elkasabany A, Srinivasan S, Berenson GS. Relation of abdominal height to cardiovascular risk factors in young adults: The bogalusa heart study. Am J Epidemiol 2000;151:885-91.

19. Silva DA, Petroski EL, Peres MA. Accuracy and measures of association of anthropometric indexes of obesity to identify the presence of hypertension in adults: A population-based study in Southern Brazil. Eur J Nutr 2013;52:237-46.

20. Liu Y, Tong G, Tong W, Lu L, Qin X. Can body mass index, waist circumference, waist-hip ratio and waist-height ratio predict the presence of multiple metabolic risk factors in Chinese subjects? BMC Public Health 2011;11:35.

21. Kodama S, Horikawa C, Fujihara K, Heianza Y, Hirasawa R, Yachi $\mathrm{Y}$, et al. Comparisons of the strength of associations with future type 2 diabetes risk among anthropometric obesity indicators, including waist-to-height ratio: A meta-analysis. Am J Epidemiol 2012;176:959-69.

22. Zabetian A, Hadaegh F, Azizi F. Appropriate cut-off values of anthropometric variables in predicting a 7.6-year risk of cardiovascular disease in Iranian adult population. J Isfahan Med Sch 2009;27:1-18.

23. Physical status: The use and interpretation of anthropometry. Report of a WHO expert committee. World Health Organ Tech Rep Ser 1995;854:1-452.

24. Fazizi F, Esmaillzadeh A, Mirmiran FP. Obesity and cardiovascular disease risk factors in Tehran adults: A population-based study. East Mediterr Health J 2004;10:887-97.
25. Kearney PM, Whelton M, Reynolds K, Whelton PK, He J. Worldwide prevalence of hypertension: A systematic review. J Hypertens 2004;22:11-9.

26. Egan BM,Zhao Y,Axon RN. US trends in prevalence, awareness, treatment, and control of hypertension, 1988-2008. JAMA 2010;303:2043-50

27. McAlister FA, Wilkins K, Joffres M, Leenen FH, Fodor G, Gee M, et al. Changes in the rates of awareness, treatment and control of hypertension in Canada over the past two decades. CMAJ 2011;183:1007-13.

28. Smith LP, Gilstad-Hayden K, Carroll-Scott A, Ickovics J. High waist circumference is associated with elevated blood pressure in non-hispanic white but not hispanic children in a cohort of pre-adolescent children. Pediatr Obes 2014;9:e145-8.

29. Song YH. The association of blood pressure with body mass index and waist circumference in normal weight and overweight adolescents. Korean J Pediatr 2014;57:79-84.

30. Okosun IS, Cooper RS, Rotimi CN, Osotimehin B, Forrester T. Association of waist circumference with risk of hypertension and type 2 diabetes in Nigerians, Jamaicans, and African-Americans. Diabetes Care 1998;21:1836-42.

31. Afrifa-Anane E, Agyemang C, Codjoe SN, Ogedegbe G, de-Graft Aikins A. The association of physical activity, body mass index and the blood pressure levels among urban poor youth in Accra, Ghana. BMC Public Health 2015;15:269.

32. Kim HK, Takahashi M, Konishi M, Tabata H, Nishimaki M, Xiang M, et al. P-46 Effects of increased daily physical activity on blood lipids and blood pressure in older adults. BMJ 2016;50(Suppl 1):A1-A90.

33. Sarikhani Y, Heydari ST, Emamghorashi F, Jafari F, Tabrizi R, Karimpour S, et al. Associated factors and standard percentiles of blood pressure among the adolescents of Jahrom City of Iran, 2014. Int J Pediatr 2017;2017:1-6.

34. Luke A, Bovet P, Plange-Rhule J, Forrester TE, Lambert EV, Schoeller DA, et al. A mixed ecologic-cohort comparison of physical activity \& weight among young adults from five populations of African origin. BMC Public Health 2014;14:397.

35. Amirkhizi F, Siasi F, Minaee s, Jalali M, Dorostimotlagh A, CHamri M. Study of blood pressure in rural women in Kerman province and its relationship with anthropometric status. J Lorestan Univ Med Sci 2008;10:31-8 